\title{
Variación espacial y estacional de grupos funcionales de bacterias cultivables del suelo de un bosque tropical seco en México
}

\author{
Noé Manuel Montaño ${ }^{1 *}$, Ana Lidia Sandoval-Pérez², Maribel Nava-Mendoza², Juan Manuel \\ Sánchez-Yañez ${ }^{3} \&$ Felipe García-Oliva ${ }^{2}$ \\ 1. Departamento de Biología (Área de Botánica), División de Ciencias Biológicas y de la Salud, Universidad Autónoma \\ Metropolitana-Iztapalapa, Apdo. 55-535,09340, D. F., México; nmma@xanum.uam.mx \\ 2. Centro de Investigaciones en Ecosistemas, Universidad Nacional Autónoma de México, Apdo. 27-3 Sta. María de \\ Guido, 58090, Morelia Michoacán, México; asandoval@oikos.unam.mx, nava@oikos.unam.mx, \\ fgarcia@oikos.unam.mx \\ 3. Microbiología Ambiental, Instituto de Investigaciones Químico-Biológicas, Universidad Michoacana de San Nicolás \\ de Hidalgo, Edificio B-1, Ciudad Universitaria, C.P. 58030, Morelia Michoacán, México; syanez@zeus.umich.mx \\ * Correspondencia
}

Recibido 06-II-2012. Corregido 08-VIII-2012. Aceptado 06-IX-2012.

\begin{abstract}
Spatial and seasonal variation of soil culturable-bacterial functional groups in a Mexican tropical dry forest. Microbial biomass and activity in soils are frequently studied in tropical dry forests, but scarce information is available about the relationships between functional bacterial groups and soil fertility, where relief interacts with rainfall seasonality. The culturable-bacterial groups and nutrients were studied during two consecutive years in soils from two topographic areas of different relief (hilltop vs hillslope) in a tropical dry forest from Chamela Jalisco, Mexico. We expected that seasonal and spatial variation in soil resources availability affects the abundance of functional culturable-bacterial groups. To evaluate this, fifteen soil cores $(1 \mathrm{~kg})$, $0-5 \mathrm{~cm}$ depth, were taken in the dry, early rainy and rainy seasons, from each of the ten replicate plots in hilltop and hillslope areas located in three microbasins. We found that hilltop soils were more organic and had higher concentration of labile $\mathrm{C}$ and total nutrient forms than hillslope soils, for which these soils had higher counts of colony-forming units (CFU) of total heterotrophic and P solubilizing bacteria. In both hilltop and hillslope soils, $\mathrm{C}$ and nutrient concentrations, as well as the counts of CFU of heterotrophic and P solubilizing bacteria generally decreased from the dry to the rainy season during the two study years. In contrast, the counts of CFU nitrifying and cellulolytic bacteria were higher at the hillslope than at the hilltop soils. The seasonal pattern of both groups was opposite to that of heterotrophic bacteria, presumably associated with a decrease in soil labile $\mathrm{C}$ and organic matter quality. In conclusion, our study suggests that available $\mathrm{C}$ appears to be the main factor that controls the structure of soil bacterial groups and soil fertility, where relief, rainfall seasonality and intra- and inter-annual variations are critical factors that interactively modify bacterial dynamics related to soil $\mathrm{C}$ availability in the tropical dry forest. Rev. Biol. Trop. 61 (1): 439-453. Epub 2013 March 01.
\end{abstract}

Key words: available C, cellulolytic bacteria, nitrifying bacteria, relief, P solubilizing bacteria, tropical deciduous forests.

Los bosques tropicales secos (BTS) tienen una amplia heterogeneidad ambiental (Campo 2003, Balvanera \& Aguirre 2006). En estos bosques la distribución de la lluvia en el año determina las entradas de materia orgánica y la humedad del suelo, que son factores críticos para las plantas y la actividad microbiana relacionados con la disponibilidad de nutrimentos
(García-Oliva et al. 2003, Montaño et al. 2007). En BTS se reporta la mayor cantidad de materia orgánica y biomasa microbiana en el suelo durante la estación seca, las cuales disminuyen en la estación húmeda debido a la descomposición y mineralización (Singh et al. 1989, Srivastava 1992, Jaramillo \& Sanford 1995, Campo et al. 1998). Asimismo, 
el accidentado relieve sobre el que se localizan estos bosques presenta crestas, valles y laderas con diferente inclinación que hacen que el transporte de materiales orgánicos y nutrimentos en el relieve sea heterogéneo, con zonas de acumulación en crestas y valles, así como zonas de ladera en donde dominan procesos de erosión, escurrimiento y lixiviación; mecanismos por los que la topografía también modifica el contenido de humedad en el perfil del suelo (Raghubanshi 1992, Roy \& Singh 1994, García-Oliva \& Maass 1998, Galicia et al. 1999, Campo 2003). Esta marcada variación temporal y espacial en algunos de los BTS puede estar modificando la disponibilidad de nutrimentos del suelo y en consecuencia, afecta el tamaño y la actividad de ciertos grupos microbianos en este ecosistema.

La disponibilidad del agua aumenta la actividad microbiana al facilitar el ingreso de sustratos oxidables, inducir la hidratación intracelular microbiana y fomentar la liberación de nutrimentos por mineralización, y de formas orgánicas por lisis microbiana debida a los cambios en el potencial hídrico (Singh et al. 1989, Campo et al. 1998, Morris \& Blackwood 2007). Además, los microorganismos del suelo aumentan o disminuyen su secreción de enzimas extracelulares en respuesta a sustratos orgánicos disponibles (Fontaine et al. 2003, Schimel \& Weintraub 2003). A pesar de que algunas investigaciones indican que los microorganismos del suelo pueden ser ubicuos y no responden a la disponibilidad de recursos (Finlay \& Clarke 1999, Finlay 2002), existen otros trabajos señalando que el tamaño y la composición de las comunidades microbianas si varían con la disponibilidad de nutrimentos en el suelo (Waldrop et al. 2000, Balser \& Firestone 2005, Noguez et al. 2005, Montaño et al. 2009). Esto sugiere que la relación entre los recursos y las comunidades microbianas en el suelo aún no son comprendidas, ya que la ubicuidad microbiana podría depender de los factores limitantes de cada ecosistema.

La heterogeneidad espacial y temporal que caracteriza a los BTS puede crear sitios y tiempos con una dinámica de nutrimentos particulares. En la estación seca, cuando existe entrada de $\mathrm{C}$ orgánico al suelo vía producción de hojarasca y de raíces, y en aquellos sitios del relieve que acumulan $\mathrm{C}$ orgánico en el suelo (COS) permiten, por ejemplo, una mayor biomasa y actividad de microorganismos heterótrofos (García-Oliva \& Maass 1998). En contraste, una menor biomasa y actividad heterotrófica podría esperarse al final de la temporada lluviosa cuando el $\mathrm{C}$ lábil es consumido por los microorganismos o lixiviado, lo cual es más marcado en sitios con menores tiempos de residencia del COS, como las laderas (Raghubanshi 1992, Jha et al. 1996, Singh \& Kashyap 2006, Montaño et al. 2007). En consecuencia, se podría esperar una variación temporal y espacial en la abundancia y tipo de grupos bacterianos activos en función de su capacidad para metabolizar distintas formas disponibles de nutrimentos (Fontaine et al. 2003, Fierer et al. 2007).

En los BTS de México los pocos estudios sobre ecología bacteriana del suelo basados en métodos de cultivo, actividad microbiana, y análisis bioquímicos y moleculares, sugieren que la composición y riqueza de las comunidades bacterianas están relacionadas a la disponibilidad de nutrimentos (Noguez et al. 2005, 2008, Montaño et al. 2009). Sin embargo, queda por conocer los grupos funcionales bacterianos activos por su especificidad a un recurso y cómo varían su abundancia con la heterogeneidad impuesta por la estacionalidad y el relieve en este ecosistema. Aunque las bacterias cultivables representan menos del $1 \%$ del total de bacterias habitando el suelo (Torsvik \& Øvreås 2002), en general los cultivos selectivos permiten estimar distintos grupos bacterianos activos en cuanto al uso de recursos, lo cual resulta en una aproximación que complementa a las realizadas con métodos bioquímicos y moleculares (Nichols 2007).

El objetivo de este estudio en un BTS fue analizar, por dos años consecutivos, el efecto de la estacionalidad de la lluvia sobre las comunidades bacterianas cultivables viables y su relación con los nutrimentos del suelo en dos posiciones topográficas del relieve (crestas 
vs. laderas). La hipótesis fue que la variación espacial y temporal de la disponibilidad de los recursos del suelo afecta la abundancia de los grupos bacterianos funcionales cultivables del suelo (heterótrofas totales, celulolíticas, solubilizadores de fosfatos y nitrificantes). Así, se esperaba que el suelo de las crestas, durante la estación de secas, presentara un mayor crecimiento y actividad bacteriana heterótrofa que el de las laderas, debido a que acumula materiales orgánicos y nutrimentos. En contraste, en el suelo de las laderas y en la estación lluviosa dominen bacterias quimiolitotróficas, debido a una disminución de materiales orgánicos por escorrentía, lixiviación y uso microbiano.

\section{MATERIALES Y MÉTODOS}

Área de estudio: Esta investigación se realizó en el bosque tropical seco de la Reserva de la Biosfera Chamela-Cuixmala, Jalisco, México $\left(19^{\circ} 29^{\prime} \mathrm{N}-105^{\circ} 01^{\prime} \mathrm{W}\right)$. La temperatura media anual es $24.6^{\circ} \mathrm{C}$ y la precipitación total anual en los años de estudio fue de $784 \mathrm{~mm}$ en 2003 y $565 \mathrm{~mm}$ en 2004 . La lluvia es fuertemente estacional con siete meses de estación seca y el $80 \%$ de la lluvia anual concentrada de junio a octubre (García-Oliva et al. 2002). El relieve dominante consiste en lomeríos con pendientes convexas con dos elementos principales: $i$ ) crestas con pendientes planas $\left(<10^{\circ}\right)$ y ii) laderas con pendientes pronunciadas $\left(18^{\circ}-35^{\circ}\right)$. El elemento dominante es la ladera que representa el $80 \%$ del área del paisaje (Galicia et al. 1995, Galicia et al. 1999, López-Blanco et al. 1999). El suelo en el sitio de estudio, es un Regosol Éutrico según la clasificación del sistema FAO (Cotler et al. 2002), tiene un $\mathrm{pH}$ de 6.8 , se desarrolla sobre riolita del Terciario y tiene una textura migajón-arcillo-arenosa, con caolinita como arcilla dominante (Campo et al. 2001a). La vegetación está compuesta por 1200 especies de plantas vasculares con un alto porcentaje de endemismos (Lott 1993), y donde la mayoría pierden sus hojas durante la estación seca (Martínez-Yrízar et al. 1996).
Diseño experimental y recolecta de suelo: Los sitios de estudio se establecieron dentro un bosque no perturbado ubicado en tres micro-cuencas hidrológicas $(16,12$ y 28 ha cada una; con un perímetro de $2090 \mathrm{~m}$ y con su canal principal orientado de este-oeste) usadas para investigación ecológica de largo plazo (Maass et al. 2002). Las microcuencas tienen el mismo material parental, tipo de vegetación y su relieve tiene diferentes unidades topográficas con distintas pendientes y orientaciones (López-Blanco et al. 1999). Para establecer los sitios de muestreo, se seleccionaron dos tipos de unidades topográficas: crestas (pendiente: $1.2^{\circ} \pm 0.7$; media $\pm \mathrm{EE}$ ) y laderas con orientación sur (pendiente: $26^{\circ} \pm 3$ ), debido a sus diferencias en las concentraciones de $\mathrm{C}$ total $(37.4 \pm 3.1$ y $24.2 \pm 1.2 \mathrm{mgC} / \mathrm{g}$ para la cresta y la ladera, respectivamente) y de $\mathrm{C}$ disponible ( $244 \pm 11$ y $92 \pm 6.1 \mu \mathrm{gC} / \mathrm{g}$ para crestas y laderas, respectivamente; véase una descripción detallada en Montaño et al. 2007). Los suelos de ambas posiciones topográficas tienen similar índice de radiación solar: 4356 y $4426 \mathrm{MJ} / \mathrm{m}^{2} /$ año para la cresta y la ladera, respectivamente (Galicia et al. 1999), textura, contenido de agua y dan soporte a un tipo de vegetación semejante (Balvanera et al. 2002). Cabe señalar que no se buscó una comparación entre microcuencas, sino que las similitudes en sus características permitieron distribuir al azar las parcelas de muestreo y maximizar el efecto de unidades topográficas que contrastan en pendiente.

El suelo fue recolectado en dos años consecutivos: 2003 y 2004, ambos con distinta distribución intra-anual de la lluvia, y en tres fechas en cada año de muestreo: estación seca (abril), inicio de lluvias (julio) y en la mitad de la estación de lluvias (septiembre); seleccionadas con base en los picos mínimos y máximos de precipitación para la zona de estudio (García-Oliva et al. 2002). Para el muestreo se establecieron 10 parcelas $(10 \times 15 \mathrm{~m})$ en las crestas y laderas-sur de las tres microcuencas experimentales. Las parcelas tenían una distancia mínima de 300m entre ellas. Las parcelas se dividieron en cuadrantes de un metro cuadrado y fueron muestreados al azar en cada una de las 
fechas. En cada parcela se recolectaron al azar 15 muestras de suelo (una de cada cuadrante) de los primeros cinco centímetros de profundidad en un área de $15 \times 15 \mathrm{~cm}$. En esta profundidad es mayor el contenido de materia orgánica en el suelo, al igual que la biomasa de raíces finas y microbiana (García-Oliva \& Maass 1998, Kummerow et al. 1990). Las 15 muestras fueron mezcladas para formar una sola muestra compuesta por parcela; la muestras fueron tamizadas con una malla de dos milímetros, almacenadas en bolsas negras y mantenidas en refrigeración $\left(10^{\circ} \mathrm{C}\right)$ hasta su procesamiento en el laboratorio en los primeros 15 días posteriores a la recolecta de suelo.

Análisis bacteriológico: Los grupos funcionales de bacterias considerados fueron: heterótrofas, celulolíticas, solubilizadoras de fósforo y nitrificantes, los cuales se cuantificaron usando $10 \mathrm{~g}$ de suelo fresco de cada muestra compuesta, procesados bajo condiciones estériles. Las unidades formadoras de colonias (UFC) de estos grupos de bacterias fueron evaluadas mediante conteos en placa (Zuberer 1994), mientras que las bacterias nitrificantes fueron cuantificadas por el método del número más probable (NMP) (Alexander 1982). Para esto se obtuvieron diluciones decimales seriadas desde $10^{-1}$ hasta $10^{-5}$ de cada muestra de suelo en agua desionizada estéril. Posteriormente, dichas diluciones fueron inoculadas en cajas Petri que contenían los medios de cultivo sólidos correspondientes según el grupo bacteriano. Para la cuantificación de bacterias, $0.1 \mathrm{~mL}$ de inóculo fue transferido por triplicado a cajas Petri con Agar de Soya Tripticaseina (AST; Bioxon ${ }^{\circledR}$ ) para las heterótrofas totales; con Agar nutritivo rico en celulosa $(\mathrm{pH}$ 6.5; $5.0 \mathrm{~mL}$ solución salina estándar de Winogradsky; $1 \mathrm{~g} \mathrm{NH}_{4} \mathrm{NO}_{3}$, solución de micro-nutrimentos $2 \mathrm{~mL} ; 10 \mathrm{~g}$ carboximetil celulosa; en $1 \mathrm{~L}$ de agua destilada) para las celulolíticas y con medio de cultivo Picovskaya [glucosa, $10 \mathrm{~g} ; \mathrm{Ca}\left(\mathrm{PO}_{4}\right)_{2}$, $5 \mathrm{~g} ;\left(\mathrm{NH}_{4}\right) \mathrm{SO}_{4}, 0.5 \mathrm{~g} ; \mathrm{KCl}, 0.2 \mathrm{~g} ; \mathrm{MgSO}_{4} \times 7 \mathrm{H}_{2} \mathrm{O}$, $0.1 \mathrm{~g} ; \mathrm{MnSO}_{4} 0.002 \mathrm{~g} ; \mathrm{FeSO}_{4} \times \mathrm{H}_{2} \mathrm{O} 0.003 \mathrm{~g}$; extracto de levadura, $0.5 \mathrm{~g}$; agar, $15 \mathrm{~g}$; en $1 \mathrm{~L}$ de agua destilada] para las solubilizadoras de fosfato. Las cajas Petri inoculadas fueron incubadas a $25^{\circ} \mathrm{C}$ y las UFC fueron contadas después de tres días para las heterótrofas y después de siete días en el caso las celulolíticas y solubilizadoras de fosfato. Para las bacterias celulolíticas se empleó $\mathrm{NaOH} 1.0 \mathrm{M}$, y rojo Congo para revelar su actividad (formación de un halo de solubilización alrededor de la colonia). El grupo quimiolitotrófico nitrificante representado por bacterias oxidadoras de amonio fue cuantificado y determinado usando carbonato de calcio enriquecido con amonio $\left[\left(\mathrm{NH}_{4}\right)_{2} \mathrm{SO}_{4}, 0.5 \mathrm{~g} ; \mathrm{K}_{2} \mathrm{PO}_{4}, 1.0 \mathrm{~g} ; \mathrm{FeSO}_{4} 7 \mathrm{H}_{2} \mathrm{O}\right.$, $0.03 \mathrm{~g} ; \mathrm{NaCl}, 0.3 \mathrm{~g} ; \mathrm{MgSO}_{4} 7 \mathrm{H}_{2} \mathrm{O}, 0.3 \mathrm{~g} ; \mathrm{CaCO}_{3}$, $7.5 \mathrm{~g}$; agua desionizada estéril] como medio de cultivo solidificado con agar (Bioxon $\left.{ }^{\circledR}\right)$ en tubos de ensayo. Un inóculo de $0.1 \mathrm{~mL}$ de cada dilución fue transferido a los tubos de ensayo con el medio, por quintuplicado. Los tubos fueron incubados por seis semanas a $25^{\circ} \mathrm{C}$. Después del periodo de incubación cada tubo fue sometido a una prueba de detección de nitritos con el reactivo Griess-Ilosvay. El número de tubos positivos y negativos identificados con esta prueba se utilizó para calcular las UFC y estimar el NMP (Alexander 1982).

Análisis fisicoquímico del suelo: Una sub-muestra de suelo fue secada a $75^{\circ} \mathrm{C}$ hasta peso constante para medir el contenido de humedad del suelo por el método gravimétrico. $\mathrm{El} \mathrm{pH}$ fue medido en una relación suelo:agua desionizada (1:2 p/v) y un potenciómetro (Corning $\left.{ }^{\circledR}\right)$.Todas las formas de $\mathrm{C}$ se determinaron con un Analizador de Carbono Total UIC Mod. CM5012 (UIC 1995), mientras que en un Analizador Bran-Luebbe III (Norderstedt, Alemania) se determinaron las formas de $\mathrm{N}$ y de $\mathrm{P}$. Una sub-muestra de suelo seco se molió en un mortero de ágata para la cuantificación de los nutrimentos totales. El C total fue determinado por combustión y detección coulométrica (UIC 1995). El N total fue determinado después de una digestión ácida por el método macro-Kjeldahl y determinado colorimétricamente (Technicon 1977). El P total fue determinado por digestión ácida por el método del molibdato seguido de una reducción con ácido ascórbico 
(Murphy \& Riley 1962) y fue cuantificado por colorimetría (Technicon 1977). El C lábil fue extraído en $\mathrm{K}_{2} \mathrm{SO}_{4}$ y cuantificado por coulometría (UIC 1995). El N inorgánico (amonio más nitrato) fue extraído con $\mathrm{KCl} 2 \mathrm{M}$, filtrado en papel Whatman ${ }^{\circledR}$ No.1 (Robertson et al. 1999) y determinado colorimétricamente por el método de hipoclorito-fenólico (Technicon 1977). El P inorgánico se extrajo con bicarbonato de sodio $(\mathrm{pH} 8.5)$ y fue determinado por el método de molibdato de ácido ascórbico (Murphy \& Riley 1962).

En todos los casos los datos fueron expresados con base en el peso seco del suelo. Un análisis de varianza de medidas repetidas (RMANOVA) con un factor entre grupos (posición: cresta y ladera), y dos factores dentro de grupos (fechas y años) fue usado para analizar los datos. Cuando hubo diferencias significativas con el RMANOVA los promedios se compararon con la prueba de Tukey (von Ende
1993). Los datos se trasformaron a logaritmos para ajustarlos a la distribución normal cuando se requirió (Sokal \& Rohlf 1995) y se presentan en su escala original de medición. Se usó un análisis de correlación Pearson para explorar alguna relación entre las UFC bacterianas y los nutrimentos del suelo. Todos los análisis se realizaron en el programa Statistica ${ }^{\circledR}$ vers. 6 (Statsoft 2000) y los promedios se consideraron significativamente diferentes con $p \leq 0.05$.

\section{RESULTADOS}

Propiedades físicas y químicas del suelo: $\mathrm{El} \mathrm{pH}$ del suelo fue ligeramente ácido (6.3-6.8) y, sólo durante 2004, el suelo de ladera tuvo valores más bajos que el suelo de la cresta (Cuadros 1 y 2). La variación estacional del pH fue mínima, sólo el suelo de ladera en 2003 fue más acido durante las lluvias. En contraste,

\section{CUADRO 1}

Valores de F y niveles de significancia del ANOVA de medidas repetidas para las variables abióticas y bióticas del suelo de dos posiciones topográficas (crestas y laderas) en un bosque tropical seco en Chamela Jalisco, México

TABLE 1

$F$-ratios and significant levels of the repeated measures ANOVA for abiotic and biotic variables of soil samples from two topographic positions (hilltop and hillslope) in a tropical dry forest at Chamela Jalisco, Mexico

\begin{tabular}{|c|c|c|c|c|c|c|c|}
\hline & \multicolumn{7}{|c|}{ F-ANOVA } \\
\hline & Posición (P) & Año (A) & $\mathrm{P} \times \mathrm{A}$ & Estación (E) & $\mathrm{P} \times \mathrm{E}$ & $\mathrm{A} \times \mathrm{E}$ & $\mathrm{P} \times \mathrm{A} \times \mathrm{E}$ \\
\hline $\mathrm{pH}$ & $1.2^{\mathrm{ns}}$ & $0.7^{\mathrm{ns}}$ & $13.2^{* *}$ & $0.52^{\mathrm{ns}}$ & $0.42^{\mathrm{ns}}$ & $5.5^{*}$ & $4.8^{*}$ \\
\hline Humedad & $17.5^{* *}$ & $51.4^{* * *}$ & $0.62^{\text {ns }}$ & $390.8^{* * *}$ & $0.81^{\mathrm{ns}}$ & $221.3^{* * *}$ & $0.09^{\text {ns }}$ \\
\hline $\mathrm{C}$ total & $80.1^{* * *}$ & $0.70^{\mathrm{ns}}$ & $0.60^{\mathrm{ns}}$ & $6.2^{*}$ & $0.10^{\mathrm{ns}}$ & $7.2^{* *}$ & $0.17^{\mathrm{ns}}$ \\
\hline $\mathrm{N}$ total & $4.6^{*}$ & $80.1^{* *}$ & $0.18^{\mathrm{ns}}$ & $12.9^{* * *}$ & $0.91^{\mathrm{ns}}$ & $22.6^{* * *}$ & $0.05^{\mathrm{ns}}$ \\
\hline P total & $6.2^{*}$ & $7.8^{*}$ & $1.04^{\mathrm{ns}}$ & $2.7^{\mathrm{ns}}$ & $0.34^{\mathrm{ns}}$ & $23.2^{* * *}$ & $0.35^{\mathrm{ns}}$ \\
\hline Cociente C:N & $8.5^{*}$ & $26.1^{* *}$ & $0.46^{\mathrm{ns}}$ & $3.9^{*}$ & $0.76^{\mathrm{ns}}$ & $4.9^{*}$ & $1.07^{\mathrm{ns}}$ \\
\hline $\mathrm{C}$ lábil- $\mathrm{K}_{2} \mathrm{SO}_{4}$ & $130.6^{* * *}$ & $36.1^{* * *}$ & $5.3^{*}$ & $149.4^{* * *}$ & $17.3^{* *}$ & $5.1^{*}$ & $0.47^{\mathrm{ns}}$ \\
\hline N inorgánico & $13.9^{* *}$ & $2.9^{\mathrm{ns}}$ & $22.6^{* * *}$ & $0.8^{\mathrm{ns}}$ & $2.7^{\mathrm{ns}}$ & $6.8^{* * * *}$ & $1.9^{\mathrm{ns}}$ \\
\hline $\mathrm{Pi}-\mathrm{NaHCO}_{3}^{-}$ & $0.08^{\mathrm{ns}}$ & $3.5^{\mathrm{ns}}$ & $3.1^{\mathrm{ns}}$ & $2.4^{\mathrm{ns}}$ & $33.3^{* * *}$ & $42.2^{* * *}$ & $5.4^{*}$ \\
\hline \multicolumn{8}{|l|}{ Bacterias } \\
\hline Heterótrofas & $30.7^{* * *}$ & $44.2^{* * *}$ & $18.3^{* *}$ & $19.1^{* *}$ & $5.8^{*}$ & $5.9^{*}$ & $2.9^{\mathrm{ns}}$ \\
\hline Celulolíticas & $0.17^{\mathrm{ns}}$ & $195.1^{* * *}$ & $6.8^{*}$ & $2.5^{\mathrm{ns}}$ & $11.1^{*}$ & $182.5^{* * *}$ & $13.4^{* *}$ \\
\hline Solubilizadoras de $\mathrm{PO}_{4}$ & $9.4^{*}$ & $11.8^{* *}$ & $3.8^{\mathrm{ns}}$ & $25.3^{* * *}$ & $0.85^{\mathrm{ns}}$ & $16.4^{* *}$ & $0.55^{\mathrm{ns}}$ \\
\hline Nitrificantes & $1.87^{\mathrm{ns}}$ & $7.5^{*}$ & $0.02^{\mathrm{ns}}$ & $5.6^{*}$ & $3.2^{*}$ & $1.9^{\mathrm{ns}}$ & $3.7^{\mathrm{ns}}$ \\
\hline
\end{tabular}

Nota: ns $=$ no significativa, ${ }^{*} \mathrm{p}<0.05 ;{ }^{* *} \mathrm{p}<0.01 ;{ }^{* * *} \mathrm{p}<0.001$

Note: $\mathrm{ns}=$ not significant, ${ }^{*} \mathrm{p}<0.05 ;{ }^{* *} \mathrm{p}<0.01 ;{ }^{* * *} \mathrm{p}<0.001$. 
CUADRO 2

Promedios ( \pm error estándar) estacionales durante dos años consecutivos de las propiedades del suelo de dos posiciones topográficas (crestas y laderas) en un bosque tropical seco en Chamela Jalisco, México

TABLE 2

Seasonal means ( \pm standard error) of soil properties on two topographic positions (hilltop and hillslope) measured during two consecutive years in a tropical dry forest at Chamela Jalisco, Mexico

\begin{tabular}{|c|c|c|c|c|}
\hline & \multicolumn{2}{|c|}{2003} & \multicolumn{2}{|c|}{2004} \\
\hline & Cresta & Ladera & Cresta & Ladera \\
\hline \multicolumn{5}{|l|}{$\mathrm{pH}\left(1: 2 \mathrm{H}_{2} \mathrm{O} \mathrm{p} / \mathrm{v}\right)$} \\
\hline Seca & $6.5(0.1)^{\mathrm{aA}}$ & $6.7(0.1)^{\mathrm{aA}}$ & $6.6(0.1)^{\mathrm{aA}}$ & $6.2(0.1)^{\mathrm{aB}}$ \\
\hline Inicio de lluvias & $6.3(0.2)^{\mathrm{aA}}$ & $6.6(0.1)^{\mathrm{aA}}$ & $6.8(0.1)^{\mathrm{aA}}$ & $6.5(0.1)^{\mathrm{aB}}$ \\
\hline Lluvias & $6.4(0.1)^{\mathrm{aA}}$ & $6.3(0.1)^{\mathrm{bA}}$ & $6.6(0.1)^{\mathrm{aA}}$ & $6.5(0.1)^{\mathrm{aB}}$ \\
\hline \multicolumn{5}{|l|}{ Humedad (\%) } \\
\hline Seca & $2.1(0.3)^{\mathrm{cA}}$ & $1.9(0.5)^{\mathrm{cB}}$ & $2.7(0.8)^{\mathrm{cA}}$ & $1.8(0.6)^{\mathrm{cB}}$ \\
\hline Inicio de lluvias & $8.4(0.5)^{\mathrm{bA}}$ & $6.7(0.7)^{\mathrm{bB}}$ & $15.9(0.5)^{\mathrm{aA}}$ & $12.3(0.9)^{\mathrm{aB}}$ \\
\hline Lluvias & $26.0(0.6)^{\mathrm{aA}}$ & $22.7(1.1)^{\mathrm{aB}}$ & $6.6(0.4)^{\mathrm{bA}}$ & $4.8(0.3)^{\mathrm{bB}}$ \\
\hline \multicolumn{5}{|l|}{$\mathrm{C}$ total $(\mathrm{mg} / \mathrm{g})$} \\
\hline Seca & $36.4(2.9)^{\mathrm{aA}}$ & $26.1(2.6)^{\mathrm{aB}}$ & $30.4(2.5)^{\mathrm{aA}}$ & $21.3(1.8)^{\mathrm{aB}}$ \\
\hline Inicio de lluvias & $34.7(2.4)^{\mathrm{aA}}$ & $24.0(3.9)^{\mathrm{aB}}$ & $31.7(1.2)^{\mathrm{aA}}$ & $21.5(1.9)^{\mathrm{aB}}$ \\
\hline Lluvias & $27.4(1.5)^{\mathrm{bA}}$ & $16.4(2.3)^{\mathrm{bB}}$ & $30.7(1.8)^{\mathrm{aA}}$ & $23.4(1.6)^{\mathrm{aB}}$ \\
\hline \multicolumn{5}{|l|}{$\mathrm{N}$ total $(\mathrm{mg} / \mathrm{g})$} \\
\hline Seca & $2.9(0.2)^{\mathrm{aA}}$ & $2.4(0.1)^{\mathrm{aB}}$ & $3.3(0.2)^{\mathrm{aA}}$ & $2.9(0.2)^{\mathrm{aB}}$ \\
\hline Inicio de lluvias & $2.3(0.1)^{\mathrm{bA}}$ & $2.0(0.8)^{\mathrm{bB}}$ & $3.1(0.2)^{\mathrm{aA}}$ & $2.8(0.2)^{\mathrm{aB}}$ \\
\hline Lluvias & $1.4(0.2)^{\mathrm{cA}}$ & $1.2(0.1)^{\mathrm{cB}}$ & $3.4(0.1)^{\mathrm{aA}}$ & $3.2(0.1)^{\mathrm{aB}}$ \\
\hline \multicolumn{5}{|l|}{ P total $(\mathrm{mg} / \mathrm{g})$} \\
\hline Seca & $0.32(0.02)^{\mathrm{aA}}$ & $0.24(0.01)^{\mathrm{aB}}$ & $0.24(0.02)^{\mathrm{aA}}$ & $0.20(0.01)^{\mathrm{aB}}$ \\
\hline Inicio de lluvias & $0.28(0.02)^{\mathrm{aA}}$ & $0.23(0.02)^{\mathrm{aB}}$ & $0.23(0.02)^{\mathrm{aA}}$ & $0.20(0.01)^{\mathrm{aB}}$ \\
\hline Lluvias & $0.24(0.02)^{\mathrm{bA}}$ & $0.18(0.01)^{\mathrm{bB}}$ & $0.26(0.02)^{\mathrm{aA}}$ & $0.22(0.01)^{\mathrm{aB}}$ \\
\hline \multicolumn{5}{|l|}{$\mathrm{C}: \mathrm{N}$} \\
\hline Seca & $13.2(1.6)^{\mathrm{bA}}$ & $12.1(3.3)^{\mathrm{bB}}$ & $9.2(0.9)^{\mathrm{aA}}$ & $7.2(0.5)^{\mathrm{aB}}$ \\
\hline Inicio de lluvias & $15.7(1.4)^{\mathrm{bA}}$ & $11.5(2.9)^{\mathrm{bB}}$ & $11.1(1.3)^{\mathrm{aA}}$ & $7.3(0.7)^{\mathrm{aB}}$ \\
\hline Lluvias & $24.8(0.6)^{\mathrm{aA}}$ & $16.4(1.7)^{\mathrm{aB}}$ & $9.3(0.6)^{\mathrm{aA}}$ & $7.5(0.5)^{\mathrm{aB}}$ \\
\hline \multicolumn{5}{|c|}{ C-lábil-K $\mathrm{SO}_{4}(\mu \mathrm{g} / \mathrm{g})$} \\
\hline Seca & $499.3(36)^{\mathrm{aA}}$ & $198.2(21)^{\mathrm{aB}}$ & $612.3(35)^{\mathrm{aA}}$ & $372.1(9.7)^{\mathrm{aB}}$ \\
\hline Inicio de lluvias & $221.2(23)^{\mathrm{bA}}$ & $78.2(20)^{\mathrm{bB}}$ & $307.3(13)^{\mathrm{bA}}$ & $248.8(13)^{\mathrm{bB}}$ \\
\hline Lluvias & $231.4(33)^{\mathrm{bA}}$ & $46.4(10)^{\mathrm{bB}}$ & $239.1(27)^{\mathrm{cA}}$ & $165.9(22)^{\mathrm{cB}}$ \\
\hline \multicolumn{5}{|c|}{$\mathrm{N}$ inorgánico $(\mu \mathrm{g} / \mathrm{g})$} \\
\hline Seca & $34.7(3.1)^{\mathrm{aB}}$ & $40.6(6.7)^{\mathrm{aA}}$ & $32.5(3.1)^{\mathrm{aA}}$ & $33.7(2.2)^{\mathrm{abA}}$ \\
\hline Inicio de lluvias & $21.1(1.4)^{\mathrm{bB}}$ & $37.6(1.4)^{\mathrm{aA}}$ & $36.1(5.1)^{\mathrm{aA}}$ & $35.4(5.1)^{\mathrm{aA}}$ \\
\hline Lluvias & $25.0(1.1)^{\mathrm{bB}}$ & $50.3(6.3)^{\mathrm{aA}}$ & $25.1(3.3)^{\mathrm{bA}}$ & $30.2(3.1)^{\mathrm{bA}}$ \\
\hline \multicolumn{5}{|c|}{$\mathrm{Pi}-\mathrm{NaHCO}_{3}{ }^{-}(\mu \mathrm{g} / \mathrm{g})$} \\
\hline Seca & $22.9(1.2)^{\mathrm{cB}}$ & $34.4(2.4)^{\mathrm{aA}}$ & $40.1(2)^{\mathrm{aA}}$ & $37.8(3)^{\mathrm{aA}}$ \\
\hline Inicio de lluvias & $44.0(1.4)^{\mathrm{aA}}$ & $31.7(2.1)^{\mathrm{bA}}$ & $29.2(4)^{\mathrm{bB}}$ & $42.7(8)^{\mathrm{aA}}$ \\
\hline Lluvias & $33.7(1.1)^{\mathrm{bA}}$ & $33.1(0.9)^{\mathrm{abA}}$ & $32.3(3)^{\mathrm{bA}}$ & $17.1(3)^{\mathrm{bB}}$ \\
\hline
\end{tabular}

Letras mayúsculas distintas indican que los promedios son significativamente diferentes $(\mathrm{p} \leq 0.05)$ entre posiciones topográficas dentro de una fecha de muestreo; mientras que letras minúsculas indican diferencias significativas $(\mathrm{p} \leq 0.05$ ) entre fechas de muestreo dentro de una misma posición topográfica.

Different uppercase letter indicate that means are significantly different $(\mathrm{p} \leq 0.05)$ between topographic positions within sampling date, whereas different lowercase letters indicate that means are significantly different among sampling dates within a topographic position. 
el suelo de la cresta tuvo mayor contenido de humedad que el suelo de la ladera, aunque estas diferencias fueron menores al $4 \%$ y la humedad fue menor en el suelo de la estación seca en ambas posiciones topográficas en los dos años (Cuadros 1 y 2).

El suelo de la cresta tuvo mayores concentraciones de $\mathrm{C}, \mathrm{N}$ y $\mathrm{P}$ totales que el suelo de ladera. En 2003, la concentración de estos nutrimentos decreció de la estación seca a la estación lluviosa, pero en 2004 no varió estacionalmente (Cuadros 1 y 2). El cociente $\mathrm{C}: \mathrm{N}$ fue mayor en el suelo de la cresta que en la ladera en ambos años; mientras que sólo en 2003 aumentó de la estación seca a la lluviosa. La concentración de $\mathrm{C}$ orgánico lábil fue mayor en el suelo de la cresta que en el suelo de la ladera para todas las fechas de muestreo $\mathrm{y}$, en general, decreció de la estación seca a la lluviosa en ambos años de estudio (Cuadros 1 y 2). En contraste, la concentración de $\mathrm{N}$ inorgánico fue mayor en el suelo de la ladera que en la cresta durante el 2003, mientras que en 2004 no hubo diferencia entre las dos posiciones topográficas. La concentración de $\mathrm{N}$ inorgánico disminuyó de la estación seca a la lluviosa en el suelo de la cresta; sin embargo, en el suelo de la ladera se mantuvo sin cambio durante 2003 y aumentó al inicio de lluvias en 2004 (Cuadros 1 y 2). La interacción significativa posición $\times$ año $\times$ estación para el $\mathrm{P}$ inorgánico extractable $\left(\mathrm{Pi}-\mathrm{NaHCO}_{3}\right)$ indica que la concentración de $\mathrm{P}$ cambió de forma diferente con la variación estacional dentro de un año en particular, sugiriendo una tendencia no clara en cuanto a la disponibilidad del P para una posición topográfica o estación (Cuadros 1 y 2).

\section{Grupos bacterianos cultivables del} suelo: El número de unidades formadoras de colonias (UFC) de las bacterias heterótrofas cultivables fue mayor en el suelo de la cresta que en el de ladera durante el 2003; mientras que en 2004 las diferencias entre posiciones topográficas sólo se presentaron al inicio de la estación lluviosa (Cuadro 1, Fig. 1A). En ambas posiciones topográficas, las UFC de bacterias heterótrofas fueron más bajas en la estación lluviosa y sólo en el suelo de la cresta se observó un incremento de UFC al inicio de la estación lluviosa (Fig. 1A). En contraste, la posición topográfica no afectó las UFC de bacterias celulolíticas del suelo (Cuadro 1). Sin embargo, estas aumentaron de la estación seca a la lluviosa durante el 2003 y en ambos años la mayor cantidad de UFC celulolíticas se registró en la estación lluviosa (Fig. 1B).

El número más probable (NMP) de bacterias nitrificantes fue mayor en el suelo de la ladera que en el suelo de la cresta, al inicio y durante la estación de lluvias en 2003, así como en la estación lluviosa en 2004 (Fig. 2A). Asimismo, en ambos años de estudio, el NMP de bacterias nitrificantes del suelo aumentó de la estación seca a la lluviosa, con excepción del suelo de la cresta en 2004 (Cuadro 1, Fig. 2A). En contraste, las UFC de bacterias solubilizadoras de fosfatos fue mayor en el suelo de la cresta que en el suelo de ladera (Cuadro 1, Fig. 2B) en los dos años de estudio. En 2003 las UFC de bacterias solubilizadoras decreció de la estación seca a la lluviosa en ambas posiciones topográficas; sin embargo, en 2004 la cantidad de UFC se redujo al inicio de la estación de lluvias con respecto a las estaciones seca y lluviosa (Fig. 2B).

Relación entre nutrimentos y bacterias: La mayoría de las correlaciones significativas entre la concentración de nutrimentos y las UFC de los grupos bacterianos cultivables ocurren en 2003; no obstante, dejaron de serlo en 2004 (Cuadro 3). Las bacterias heterótrofas se correlacionaron positivamente con la concentración de nutrimentos y de $\mathrm{C}$ lábil; pero negativamente con el contenido de humedad y la concentración de $\mathrm{N}$ inorgánico. En ambos años este grupo bacteriano se correlacionó con la humedad y con el C lábil. El grupo celulolítico se correlacionó positivamente con la humedad y con el cociente $\mathrm{C}: \mathrm{N}$ y negativamente con la concentración de nutrimentos y de $\mathrm{C}$ lábil, aunque las únicas correlaciones consistentes para ambos años fueron con la concentración de C lábil y con el cociente C:N. Las UFC de solubilizadoras de fosfatos se correlacionaron 

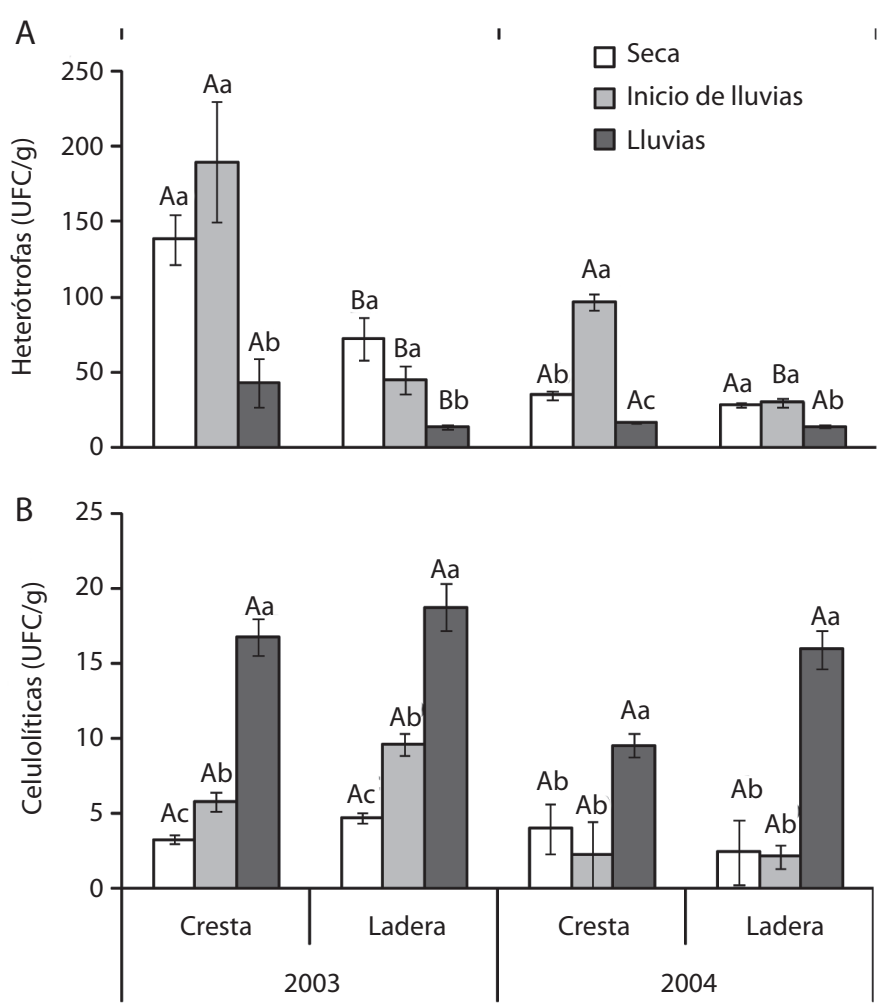

Fig. 1. Variación estacional (promedio \pm error estándar) de las unidades formadoras de colonias (UFC) de bacterias A) heterótrofas y B) celulolíticas del suelo de dos posiciones topográficas (crestas y laderas), estudio realizado durante dos años consecutivos en un bosque tropical seco en Chamela Jalisco, México. Las letras mayúsculas y minúsculas sobre las barras indican diferencias significativas según lo explicado en el Cuadro 2.

Fig. 1. Seasonal variation (mean $\pm \mathrm{SE}$ ) in culturable bacteria counts (CFU): A) heterotrophs and B) cellulolytic in soil of two topographic positions (hilltop and hillslope) in a tropical dry forest of Chemela, Mexico. Different letter on the bars indicate that means are significantly diferent such as is explained in Table 2.

positivamente con la humedad y con el cociente $\mathrm{C}: \mathrm{N}$ en 2003, pero en 2004 la correlación fue negativa con la humedad y positiva con la concentración de C lábil. Las UFC de bacterias nitrificantes se correlacionaron positivamente con la humedad y negativamente con la concentración de nutrimentos y de C lábil en 2003; mientras que en 2004 sólo hubo una correlación negativa con la concentración de C lábil (Cuadro 3).

\section{DISCUSIÓN}

La posición topográfica afectó la distribución de los recursos del suelo en función de la estacionalidad de la lluvia. El flujo del agua en el relieve distribuye los materiales orgánicos y minerales, por lo que el suelo de la cresta con menor pendiente acumuló mantillo y aumentó el tiempo de residencia de la MOS en comparación con el suelo de la ladera que es más susceptible a la remoción de la MOS por procesos erosivos (Galicia et al. 1995, García-Oliva et al. 1995). Esto podría explicar la mayor concentración de formas totales de $\mathrm{C}, \mathrm{N}$ y $\mathrm{P}$ en el suelo de la cresta. Esta tendencia ya ha sido reportada para otros BTS, en donde la ladera tiene menor concentración de MOS que la cresta, debido a que el material es removido tan rápido como se acumula (Voroney et al. 1981, Raghubanshi 1992, Roy \& Singh 1994, Montaño et al. 2007). En consecuencia, la cresta tiene un suelo más orgánico y con mayor capacidad de retención de recursos que la ladera. 

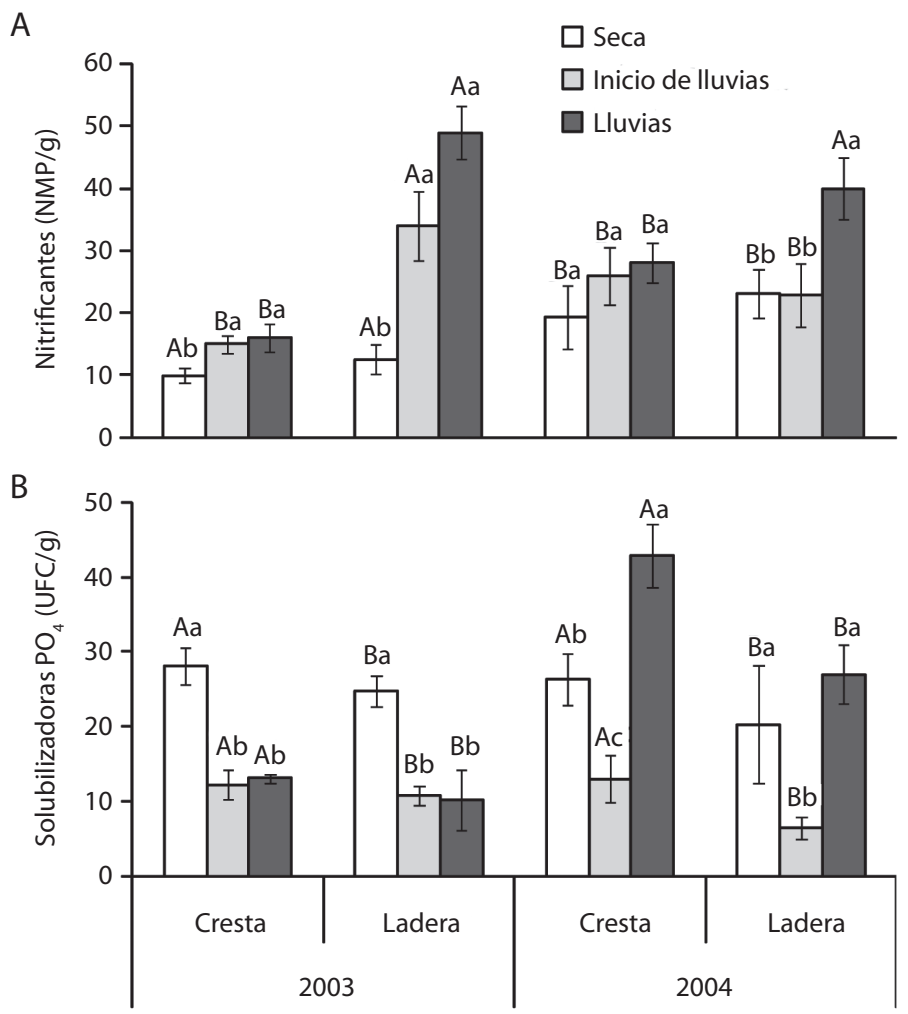

Fig. 2. Variación estacional (promedio \pm error estándar) de las unidades formadoras de colonias (UFC) de bacterias A) nitrificantes y B) solubilizadoras de fosfatos $\left(\mathrm{PO}_{4}\right)$ del suelo de dos posiciones topográficas (crestas y laderas), estudio realizado durante dos años consecutivos en un bosque tropical seco en Chamela Jalisco, México. Las letras mayúsculas y minúsculas sobre las barras indican diferencias significativas según lo explicado en el Cuadro 2.

Fig. 2. Seasonal variation (mean $\pm \mathrm{SE}$ ) in culturable bacteria counts (CFU): A) nitrifying and B) phosphate solubilizing in soil of two topographic positions (hilltop and hillslope) in a tropical dry forest of Chemela, Mexico. Different letter on the bars indicate that means are significantly diferent such as is explained in Table 2.

Las diferencias en las formas totales de nutrimentos debidas al relieve, en particular sobre el C orgánico, sugieren que las crestas favorecen la disponibilidad de $\mathrm{C}$ y nutrimentos que estimulan la actividad bacteriana. Una mayor concentración de $\mathrm{C}$ lábil en la cresta incrementó la abundancia de bacterias heterótrofas y solubilizadoras de $\mathrm{P}$ del suelo de esta posición topográfica en comparación con la ladera (Noguez et al. 2005, 2008, Montaño et al. 2009). El C lábil proporciona energía orgánica para estos grupos bacterianos, ya que representa formas de C química y estructuralmente sencillas para ser degradadas (Hu et al. 1999, García-Oliva et al. 2003). Asimismo, la acumulación de $\mathrm{C}$ orgánico lábil durante la estación seca en ambas posiciones topográficas pudo estimular el crecimiento de las bacterias heterótrofas al inicio de las lluvias en el suelo con más C lábil (García-Oliva et al. 2003), sugiriendo que la actividad bacteriana es no sólo afectada por la humedad del suelo, sino también por la disponibilidad de energía.

La concentración de $\mathrm{N}$ y $\mathrm{P}$ inorgánico, en contraste con la de $\mathrm{C}$ lábil, aparentemente no fue afectada por la posición topográfica. En el caso del $\mathrm{N}$, esto puede asociarse a que el amonio es rápidamente transformado a óxidos de $\mathrm{N}$ y a nitrato en el suelo de los BTS, siendo estas formas químicas altamente móviles tanto dentro como fuera del perfil del suelo (GarcíaMéndez et al. 1991, Raghubanshi 1992, Florinsky et al. 2004, Montaño et al. 2007), lo que evitó establecer las posibles diferencias 
CUADRO 3

Coeficientes de correlación (Pearson) entre las concentraciones de nutrimentos y los conteos de grupos bacterianos del suelo medidos durante dos años consecutivos en un bosque tropical seco en Chamela, Jalisco México

TABLE 3

Pearson correlation coefficients for nutrient concentrations and the counts of soil bacterial groups on two topographic positions (hilltop and hillslope) measured during two consecutive years in a tropical dry forest at Chamela Jalisco, Mexico

\begin{tabular}{|c|c|c|c|c|}
\hline \multirow{2}{*}{ Año 2003 (n=60) } & \multicolumn{4}{|c|}{ Bacterias $(\mathrm{UFC} / \mathrm{g})$} \\
\hline & Heterótrofas & Celulolíticas & Solubiliza- doras de $\mathrm{PO}_{4}$ & Nitrificantes \\
\hline $\mathrm{pH}$ & 0.07 & 0.54 & -0.12 & -0.09 \\
\hline Humedad & $-0.35^{* *}$ & $0.85^{* * *}$ & $0.43^{* *}$ & $0.35^{*}$ \\
\hline C total & $0.59^{* *}$ & $-0.52^{* *}$ & 0.01 & $-0.36^{*}$ \\
\hline $\mathrm{N}$ total & $0.30^{*}$ & $-0.67^{* * *}$ & -0.29 & $-0.27^{*}$ \\
\hline P total & $0.39^{*}$ & $-0.35^{*}$ & 0.02 & $-0.23^{*}$ \\
\hline $\mathrm{C}: \mathrm{N}$ & -0.01 & $0.33^{*}$ & $0.36^{*}$ & 0.07 \\
\hline $\mathrm{C}$ lábil $\mathrm{K}_{2} \mathrm{SO}_{4}$ & $0.34^{* *}$ & $-0.49^{* *}$ & 0.11 & $-0.26^{*}$ \\
\hline $\mathrm{N}$ inorgánico & $-0.28^{*}$ & 0.24 & -0.09 & 0.11 \\
\hline $\mathrm{Pi}-\mathrm{NaHCO}_{3}^{-}$ & 0.17 & 0.04 & -0.05 & 0.01 \\
\hline \multicolumn{5}{|l|}{ Año $2004(\mathrm{n}=60)$} \\
\hline $\mathrm{pH}$ & 0.17 & -0.04 & -0.20 & 0.13 \\
\hline Humedad & $-0.47^{* *}$ & -0.19 & $-0.47^{* *}$ & 0.04 \\
\hline $\mathrm{C}$ total & 0.14 & 0.05 & -0.01 & 0.03 \\
\hline $\mathrm{N}$ total & -0.24 & 0.04 & 0.01 & -0.01 \\
\hline P total & -0.12 & 0.05 & 0.06 & 0.12 \\
\hline $\mathrm{C}: \mathrm{N}$ & 0.02 & $0.24^{*}$ & -0.04 & 0.01 \\
\hline $\mathrm{C}$ lábil $\mathrm{K}_{2} \mathrm{SO}_{4}$ & $0.38^{* *}$ & $-0.68^{* *}$ & $0.69^{* * *}$ & $-0.37^{*}$ \\
\hline N inorgánico & 0.13 & 0.17 & -0.03 & 0.01 \\
\hline${\mathrm{Pi}-\mathrm{NaHCO}_{3}^{-}}^{-}$ & -0.11 & -0.14 & 0.09 & 0.09 \\
\hline
\end{tabular}

Nota: $n s=$ no significativa, ${ }^{*} \mathrm{p}<0.05 ;{ }^{* *} \mathrm{p}<0.01 ;{ }^{* * *} \mathrm{p}<0.001$. Note: ns $=$ not significant, ${ }^{*} \mathrm{p}<0.05 ;{ }^{* *} \mathrm{p}<0.01 ;{ }^{* * *} \mathrm{p}<0.001$.

en concentración de $\mathrm{N}$ inorgánico entre crestas y laderas. Por otra parte, la redistribución del $\mathrm{Pi}-\mathrm{NaHCO}_{3}$ en el paisaje ya ha sido reportada para otros bosques (Agbenin \& Tiessen 1994). Entre los principales agentes de la redistribución del P están la escorrentía superficial y la erosión que provocan el aporte continuo en las laderas por la entrada de material coluvial rico en $\mathrm{P}$ y que se lava de las crestas. Esto podría estar ocurriendo en el suelo de las laderas del BTS de Chamela, lo que no permitió señalar las diferencias en $\mathrm{P}$ inorgánico entre las posiciones topográficas estudiadas. El movimiento de suelo de las crestas hacia las laderas y las partes bajas del relieve en este BTS ha sido demostrado en otros estudios para esta zona (Galicia et al. 1995, García-Oliva \& Maass 1998, GarcíaOliva et al. 1995).

Singh et al. (1989), Luizao et al. (1992) y Montaño et al. (2009) mostraron que la biomasa microbiana del suelo cambia estacionalmente en los BTS, lo que concuerda con la variación estacional reportada para los diferentes grupos bacterianos evaluados en este estudio. En estos bosques, existe una mayor entrada de materia orgánica aérea y subterránea en la estación seca (Kummerow et al. 1990, Martínez-Yrízar et al. 1996), la cual aportó a las comunidades bacterianas del suelo nuevos compuestos orgánicos fácilmente degradables (Campo et al. 1998, Eaton 2001, García-Oliva et al. 2003, Anaya et al. 2007, Montaño et al. 
2007) y estimuló el crecimiento de bacterias heterótrofas al inicio de la estación húmeda, principalmente en el suelo con mayor cantidad de recursos (i.e. crestas).

En contraste, durante la estación lluviosa la cantidad de bacterias heterótrofas cultivables pudo reducirse debido a una menor disponibilidad de $\mathrm{C}$ provocada por el consumo microbiano, o bien porque los nutrimentos fueron absorbidos por las raíces de las plantas y/o lixiviados (Montaño et al. 2007). En especial, la reducción en la concentración del C lábil pudo haber favorecido también la abundancia de bacterias celulolíticas, dada la dominancia de formas de $\mathrm{C}$ de menor calidad como lo indica el mayor cociente $\mathrm{C}: \mathrm{N}$ en el suelo recolectado durante la estación húmeda. Esto último coincide con la correlación negativa de la concentración del $\mathrm{C}$ lábil y la positiva del cociente $\mathrm{C}: \mathrm{N}$ con las UFC celulolíticas, respectivamente. Asimismo, las UFC celulolíticas tendieron ligeramente a incrementar durante la estación de lluvias en el suelo con menor concentración de C lábil (ladera). Así, la disponibilidad de recursos podría estar activando a bacterias con la capacidad enzimática para degradar polímeros de mayor complejidad química como es el caso de la celulosa (Atlas \& Bartha 2002, Morris \& Blackwood 2007).

La disponibilidad de recursos induce un recambio en las comunidades bacterianas asociado a las capacidades enzimáticas por parte de los diferentes grupos bacterianos (Morris \& Blackwood 2007). Por ejemplo, el C disponible estimula la inmovilización de amonio por bacterias heterótrofas, lo que podría reducir su disponibilidad para las bacterias nitrificantes. Esto explicaría la mayor abundancia de bacterias nitrificantes en el suelo de ladera con menor concentración de $\mathrm{C}$ lábil, cuyo patrón es opuesto a la cantidad de UFC de heterótrofas. Verhagen \& Laanbroek (1991) demostraron que los nitrificantes aumentan cuando las bacterias heterótrofas están limitadas por $\mathrm{C}$ disponible, debido a que obtienen energía por la oxidación del amonio y no del $\mathrm{C}$ orgánico. Otros estudios realizados en diferentes ecosistemas documentan que la disponibilidad de C del suelo favorece la inmovilización del $\mathrm{N}$ y decrece la nitrificación por un efecto negativo sobre la disponibilidad de amonio para las comunidades nitrificantes (Bernhardt \& Likens 2002, Florinsky et al. 2004, Booth et al. 2005, Montaño et al. 2009). Así, el patrón estacional de las bacterias nitrificantes podría asociarse a una reducción en la concentración del $\mathrm{C}$ lábil y en la calidad de la MOS durante la estación lluviosa; así como a la mayor disponibilidad de agua (Singh et al. 1989, Jha et al. 1996, Singh \& Kashyap 2006). Esto sugiere que las bacterias nitrificantes podrían ser favorecidas en posiciones del relieve y en tiempos en los que la disponibilidad del $\mathrm{C}$ es reducida y el agua no es limitante.

Un efecto favorable de la disponibilidad de $\mathrm{C}$ sobre abundancia de bacterias solubilizadoras de $\mathrm{P}$, como las $\beta$-Proteobacterias, las Firmicutes, y las $\gamma$-proteobacterias, ya ha sido reportado en otras investigaciones (Cleveland et al. 2007, Fierer et al. 2007). No obstante, en este estudio, las bacterias solubilizadoras tuvieron tendencias estacionales distintas entre los dos años, debido posiblemente a la diferente distribución estacional de la lluvia. En 2003, la lluvia se distribuyó homogéneamente de junio a septiembre; mientras que en 2004 se concentró sólo en julio; lo que decreció las UFC de este grupo bacteriano diferencialmente entre años por alguna de las razones siguientes: i) una menor concentración del C lábil, ii) lisis microbiana y/o pastoreo por fauna y iii) un incremento en la concentración de $\mathrm{P}$ inorgánico que inhibe a los solubilizadores dada la disponibilidad de este nutrimento. En conjunto, estas evidencias sugieren que el $\mathrm{C}$ disponible podría estar regulando parcialmente a las bacterias solubilizadoras, ya que su actividad podría ser más sensible a la variación en la humedad del suelo impuesta por la distribución intra-anual de la lluvia. Esta fuerte dependencia de la dinámica microbiana del $\mathrm{P}$ a los pulsos de humedad en este BTS ya ha sido reportada por otros estudios (Campo et al. 1998, 2001b).

Asimismo, la diferencia del $41 \%$ en la cantidad de lluvia entre 2003 y 2004 que se reflejó en la humedad del suelo, afectó la 
variación estacional de las bacterias del suelo entre años. Una mayor humedad en el suelo en 2003 favoreció la actividad de bacterias heterótrofas de rápido crecimiento que dependen del C lábil, provocando la transformación del $\mathrm{N} \mathrm{y}$ el $\mathrm{P}$, lo que marcó las diferencias estacionales en la concentración de estos nutrimentos. En contraste, en 2004 la actividad de este tipo de bacterias fue limitada por la humedad del suelo, permitiendo la actividad de bacterias celulolíticas y nitrificantes de lento crecimiento. Esto, en conjunto con los resultados anteriores, sugiere que la disponibilidad inter- e intra anual del agua controla, interactivamente con la topografía, la dinámica bacteriana y de los nutrimentos en el suelo del BTS.

En conclusión, este estudio provee evidencias sobre la importancia del relieve en la dinámica de algunos nutrimentos y grupos bacterianos funcionales en el suelo de un BTS en México. Las evidencias apoyan un modelo conceptual que ha sido desarrollado en la última década, el cual predice que la incorporación de C lábil al suelo estimula a los microorganismos estrategas " $r$ " ("priming effect") que son parcialmente eficientes en descomponer la MOS compleja (copiotróficos), pero que si las entradas de C lábil son reducidas, los estrategas "k" (oligotróficos) son los responsables de la descomposición de la MOS compleja (Hu et al. 1999, Fontaine et al. 2003, Langer et al. 2004, Fierer et al. 2007, Cleveland et al. 2007, Montaño et al. 2009, de Graaff et al. 2010). De acuerdo con este modelo, esta investigación permite hipotetizar que el $\mathrm{C}$ disponible, podría regular la abundancia de los grupos bacterianos heterotróficos con respecto a los quimiolitotróficos $\mathrm{y}$, en consecuencia, la mineralización de nutrimentos del suelo, en donde el relieve, la estacionalidad y la fluctuación inter e intra anual de la lluvia regulan, interactivamente, la dinámica de la relación bacterias-C disponible en el suelo de los BTS.

\section{AGRADECIMIENTOS}

A Carlos Anaya y Salvador Araiza por ayudar en el trabajo de laboratorio y campo.
Juan Bosco (Universidad Michoacana de San Nicolás de Hidalgo) y David Hernández (Instituto Tecnológico de Morelia) brindaron asesoría con las técnicas de cultivos bacterianos. Raúl Ahedo y Heberto Ferreira apoyaron con el análisis estadístico. N.M. Montaño agradece a Víctor Jaramillo por el espacio en el laboratorio y su asesoría en el diseño del proyecto, y al PROMEP de la Secretaria de Educación Pública de México, por la beca otorgada durante la elaboración de este artículo.

\section{RESUMEN}

Los bosques tropicales secos tienen una amplia heterogeneidad ambiental y por lo tanto se podría esperar una variación temporal y espacial en la abundancia y tipo de grupos bacterianos activos. Se evaluó, durante dos años consecutivos, el efecto de la estacionalidad de la lluvia sobre algunos grupos bacterianos cultivables y nutrimentos del suelo en dos posiciones topográficas (crestas vs laderas) en el bosque tropical seco, Chamela Jalisco, México. La hipótesis fue que la variación temporal y espacial de la disponibilidad de recursos afectaría la abundancia de los grupos bacterianos funcionales (heterótrofas totales, celulolíticas, solubilizadores de fosfatos y nitrificantes) del suelo. En las crestas, el suelo fue más orgánico y con mayor concentración de nutrimentos totales y $\mathrm{C}$ orgánico lábil que en la ladera, registrando más bacterias heterótrofas y solubilizadoras de fosfato. En ambas posiciones topográficas la concentración de $\mathrm{C}$ y nutrimentos, así como el número de bacterias heterótrofas y solubilizadoras de $\mathrm{P}$, decrecieron de la estación seca a la lluviosa en ambos años. En contraste, las bacterias nitrificantes fueron mayores en el suelo de la ladera, y al igual que las celulolíticas, tuvieron un patrón estacional opuesto a las bacterias heterótrofas, asociado a la disminución del C lábil y de la calidad de la materia orgánica. En conclusión, se sugiere que el relieve, la estacionalidad y la variación inter-anual de la lluvia regulan interactivamente la relación entre el $\mathrm{C}$ disponible y la estructura de las comunidades bacterianas del suelo en el bosque tropical seco de Chamela.

Palabras clave: bacterias celulolíticas y solubilizadoras de $\mathrm{P}$, bosque tropical caducifolio, $\mathrm{C}$ disponible, nitrificantes, relieve.

\section{REFERENCIAS}

Anaya, A.C., F. García-Oliva \& V.J. Jaramillo. 2007. Rainfall and labile carbon availability control litter nitrogen dynamics in tropical dry forest. Oecologia 150: $602-610$. 
Agbenin, J.O. \& H. Tiessen. 1994. Phosphorus transformations in a toposequence of Litosols and Cambisols from semi-arid northeastern Brazil. Geoderma 62: 345-362.

Alexander, M. 1982. Most probable number method for microbial populations, p. 1467-1472. In C.A. Black (ed.). Methods of soil analysis. Amer. Soc. Agron., Madison, EE.UU.

Atlas, R.M. \& R. Bartha. 2002. Microbial ecology: fundamentals and applications. Benjamin Cumminngs, Redwood, EE.UU.

Balser, T.C. \& M.K. Firestone. 2005. Linking microbial community composition and soil processes in a California annual grassland and mixed-conifer forest. Biogeochemistry 73: 395-415

Balvanera, P. \& E. Aguirre. 2006. Tree diversity, environmental heterogeneity and productivity in a Mexican tropical dry forest. Biotropica 38: 479-491.

Balvanera, P., E. Lott, G. Segura, C. Siebe \& A. Islas. 2002. Patterns of beta-diversity in a Mexican tropical dry forest. J. Veg. Sci. 13: 145-158.

Bernhardt, E.S. \& G. Likens. 2002. Dissolved organic carbon enrichment alters nitrogen dynamics in a forest stream. Ecology 83: 1689-1700.

Booth, M.S., J.M. Stark \& E. Rastetter. 2005. Controls on nitrogen cycling in terrestrial ecosystems: a synthetic analysis of literature data. Ecology 75: 139-157.

Campo, J. 2003. Disponibilidad y flujos de nutrimentos en una toposecuencia con bosque tropical seco en México. Agrociencia 37: 211-219.

Campo, J., V.J. Jaramillo \& J.M. Maass. 1998. Pulses of soil phosphorus availability in a Mexican tropical dry forest: effects on seasonality and level of wetting. Oecologia 115: 167-172.

Campo, J., J.M. Maass \& L. de Pablo. 2001a. Intemperismo en un bosque tropical seco de México. Agrociencia 35: 245-254.

Campo, J., J.M. Maass, V.J. Jaramillo, A. Martínez-Yrízar \& J. Sarukhán. 2001b. Phosphorous cycling in a Mexican tropical dry forest ecosystem. Biogeochemistry 53: 161-179.

Cleveland, C., D. Nemergut, S.K. Schmidt \& A.R. Townsend. 2007. Increases in soil respiration following labile carbon additions linked to rapid shifts in soil microbial community composition. Biogeochemistry 82: 229-240.

Cotler, H., E. Durán \& C. Siebe. 2002. Caracterización morfo-edafológica y calidad de sitio de un bosque tropical caducifolio, p. 17-79. In F. Noguera, J. Vega, A. García \& M. Quezada (eds.). Historia Natural de Chamela. Instituto de Biología-UNAM, D.F., México. de Graaff, M.A., A.T. Classen, H.F. Castro \& C.W. Schadt. 2010. Labile soil carbon inputs mediate the soil microbial community composition and plant residue decomposition rates. New Phytol. 188: 1055-1064.

Eaton, W.D. 2001. Microbial and nutrient activity in soils from three different subtropical forest habitats in Belize, Central America before and during the transition from dry to wet season. App. Soil Ecol. 16: 219-227.

Fierer, N., M.A. Bradford \& R.B. Jackson. 2007. Towards an ecological classification of soil bacteria. Ecology 88: 1354-1364.

Finlay, B.J. 2002. Global dispersal of free-living microbial eukaryote species. Science 296: 1061-1063.

Finlay, B.J. \& K.J. Clark. 1999. Ubiquitous dispersal of microbial species. Nature 400: 828.

Florinsky, I.V., S. McMahon \& D.L. Burton. 2004. Topographic control of soil microbial activity: a case study of denitrifiers. Geoderma 119: 33-53.

Fontaine, S., A. Mariotti \& L. Abbadie. 2003. The priming effect of organic matter: a question of microbial competition. Soil Biol. Biochem. 35: 837-843.

Galicia, L., F. García-Oliva \& J. López-Blanco. 1995. Efecto de la estructura jerárquica del relieve en la distribución de las características físicas de los suelos en una cuenca tropical estacional mexicana. Bol. Invest. Geog. 13: 53-75.

Galicia, L., J. López-Blanco, A.E. Zarco-Arista, V. Filips \& F. García-Oliva. 1999. The relationship between solar radiation interception and soil water content in a tropical deciduous forest in Mexico. Catena 36: 153-164.

García-Méndez, G., J.M. Maass, P. Matson \& P. Vitousek. 1991. Nitrogen transformations and nitrous oxide flux in a tropical deciduous forest in Mexico. Oecologia 88: 362-366.

García-Oliva, F., R. Martínez-Lugo \& J.M. Maass. 1995. Long-term net soil erosion as determined by $137 \mathrm{Cs}$ redistribution in an undisturbed and perturbed tropical deciduous forest ecosystem. Geoderma 68: 135-147.

García-Oliva, F. \& J.M. Maass. 1998. Efecto de la transformación de la selva a pradera sobre la dinámica de los nutrientes en un ecosistema tropical estacional en México. Bol. Soc. Bot. México 62: 39-48.

García-Oliva, F., A. Camu \& J.M. Maass. 2002. El clima de la Región de Central de la costa del Pacífico Mexicano, p. 3-10. In F. Noguera, J. Vega, A. García \& M. Quezada (eds.). Historia Natural de Chamela. Instituto de Biología UNAM, D.F., México.

García-Oliva, F., B. Sveshtarova \& M. Oliva. 2003. Seasonal effect on soil organic carbon dynamics in a tropical deciduous forest ecosystem in western Mexico. J. Trop. Ecol. 19: 1-11. 
Hu, S.J., A.H. Van Bruggen \& N.J. Grünwald. 1999. Dynamics of bacterial populations in relation to carbon availability in a residue-amended soil. App. Soil Ecol. 13: 21-30.

Jaramillo, V.J. \& R.L. Sanford Jr. 1995. Nutrient cycling in tropical deciduous forest, p. 346-361 In S. H. Bullock, H.A. Mooney \& E. Medina (eds.). Seasonally dry tropical forest. Cambridge University, Cambridge, EE.UU.

Jha, P.B., J.S. Singh \& A.K. Kashyap. 1996. Dynamics of viable nitrifier community and nutrient availability in dry tropical forest habitat as affected by cultivation and soil texture. Plant Soil 180: 277-285.

Kummerow, J., J. Castellanos, J.M. Maass \& A. Larigauderie. 1990. Productions of fine roots and the seasonality of their growth in a Mexican deciduous dry forest. Vegetatio 90: 73-80.

Langer, U., L. Böhme \& F. Böhme. 2004. Classification of soil microorganisms based on growth properties: a critical view of some commonly used terms. J. Plant Nutr. Soil Sci. 167: 267-269.

López-Blanco, J., L. Galicia \& F. García-Oliva. 1999. Hierarchical analysis of relief features in a small watershed in a tropical deciduous forest ecosystem in Mexico. Supp. Geog. Fis. Dinam. Quat. 22: 33-40.

Lott, E.J. 1993. Annotated checklist of the vascular flora of the Chamela Bay region, Jalisco, Mexico. Occ. Papers Calif. Acad. Sci. 148: 1-60.

Luizao, R.C., T.A. Bonde \& T. Rosswall. 1992. Seasonal variation of soil microbial biomass. The effects of clearfelling or tropical rainforest and establishment of pasture in the Central Amazon. Soil Biol. Biochem. 8: $805-813$

Maass, J.M.,V. Jaramillo, A. Martínez-Yrízar, F. García-Oliva, A. Pérez-Jiménez \& J. Sarukhán. 2002. Aspectos funcionales del ecosistema de la selva baja caducifolia en Chamela, Jalisco, p. 525-551 In F. Noguera, J. Vega, A. García \& M. Quezada (eds.). Historia Natural de Chamela. Instituto de Biología UNAM, D.F., México.

Martínez-Yrízar, A., J.M. Maass, A. Pérez-Jiménez \& J. Sarukhán. 1996. Net primary productivity of a tropical deciduous forest ecosystem in western Mexico. J. Trop. Ecol. 12: 169-175.

Montaño, N.M., F. García-Oliva \& V.J. Jaramillo. 2007. Dissolved organic carbon affects soil microbial and nitrogen dynamics in a Mexican tropical deciduous forest. Plant Soil 295: 265-277.

Montaño, N.M., A.L. Sandoval-Pérez, F. García-Oliva, J. Larsen \& M.E. Gavito. 2009. Microbial activity in contrasting conditions of soil $\mathrm{C}$ and $\mathrm{N}$ availability in a tropical dry forest. J. Trop. Ecol. 25: 401-413.

Morris, S.J. \& C.B. Blackwood. 2007. The ecology of soil organisms, p. 195-229 In E. Paul (ed.). 2007. Soil microbiology and biochemistry. Academic, Nueva York, EE.UU.

Murphy, J. \& J.P. Riley 1962. A modified single solution method for the determination of phosphate in natural waters. Anal. Chim. Acta 27: 31-36.

Nichols, D. 2007. Cultivation gives context to the microbial ecologist. FEMS-Microb. Ecology 60: 351-367.

Noguez, A.M., H.T. Arita, A. Escalante, L.J. Forney, F. García-Oliva \& V. Souza. 2005. Microbial macroecology: highly structured prokaryotic soil assemblages in a tropical deciduous forest. Global Ecol. Biogeo. 14: $241-248$.

Noguez, A.M., A. Escalante, L. Forney, M. Nava-Mendoza, I. Rosas, V. Souza \& F. García-Oliva. 2008. Soil aggregates in a tropical deciduous forest: effects on $\mathrm{C}$ and $\mathrm{N}$ dynamics, and microbial communities as determined by t-RFLPs. Biogeochemistry 19: 209-220.

Raghubanshi, A.S. 1992. Effect of topography on selected soil properties and nitrogen mineralization in a dry tropical forest. Soil Biol. Biochem. 24: 145-150.

Robertson, P.G., D.C. Coleman, C.S. Bledsoe \& P. Sollins. 1999. Standard soil methods for long-term ecological research (LTER). Oxford University, Oxford, EE.UU.

Roy, S. \& J.S. Singh. 1994. Consequences of habitat heterogeneity for availability of nutrients in a dry tropical forest. J. Ecol. 82: 503-509.

Schimel, J.P. \& M.N. Weintraub. 2003. The implications of exoenzyme activity on microbial $\mathrm{C}$ and $\mathrm{N}$ limitation in soil: a theoretical model. Soil Biol. Biochem. 35: 549-563.

Singh, J.S. \& A.K. Kashyap. 2006. Dynamics of viable nitrifier community, $\mathrm{N}$ mineralization and nitrification in seasonally dry tropical forests and savanna. Microbiol. Res. 161: 169-179.

Singh, J.S., S. Raghubanshi, R.S. Singh \& C. Srivastava. 1989. Microbial biomass acts as a source of plant nutrients in dry tropical forest and savanna. Nature 338: 499-500.

Sokal, R. \& F. Rohlf. 1995. Biometry. Freeman and Company, San Francisco EE.UU.

Srivastava, S.C. 1992. Microbial C, N, and P in dry tropical soils: seasonal changes and influence of soil moisture. Soil Biol. Biochem. 24: 711-714.

StatSoft. 2000. Statistica ver. 6.0. for Windows [Computer program manual]. Tulsa, Oklahoma, EE.UU

Technicon. 1977. Technicon industrial System. Method No. 329-74W/B Individual/simultaneous determinations of nitrogen and/or phosphorus in $\mathrm{BD}$ acid digest. Technicon Industrial Systems, Nueva York, EE.UU.

Torsvik, V. \& L. Øvreås. 2002. Microbial diversity and function in soil: from genes to ecosystems. Curr. Op. Microbiol. 5: 240-245. 
UIC. 1995. Operation manual for the CM5012 CO2 Colourmeter. UIC Joliet Illinois, EE.UU.

Verhagen, F.J. \& H.J. Laanbroek. 1991. Competition for ammonium between nitrifying and heterotrophic bacteria in energy-limited chemostats. App. Environ. Microb. 57: 3255-3263.

von Ende, C.N. 1993. Repeated measures analysis: growth and other time-dependent measures, p. 113-137. In S.M. Scheiner \& J. Gurevitch (eds.). Design and analysis of ecological experiments. Chapman and Hall, Nueva York, EE.UU.
Voroney, R.P., J.A. Van Veen \& E.A. Paul. 1981. Organic C dynamics in grassland soils: 2 . Model validation and simulation of the long-term effects of cultivation and rainfall erosion. Can. J. Soil Sci. 61: 211-224.

Waldrop, M.P., T. Balser \& M.K. Firestone. 2000. Linking microbial community composition to function in a tropical soil. Soil Biol. Biochem. 32: 1837-1846.

Zuberer, D.A. 1994. Recovery and enumeration of viable bacteria, p. 119-144. In R.W. Weaver (ed.). Methods of soil analysis, part 2: microbiological and biochemical properties. SSSA Book series: 5. Soil Sci. Soc. Amer., Madison, EE.UU. 
